\title{
MANEJO TERAPÊUTICO DO HEPATOCARCINOMA FIBROLAMELAR
}

\author{
MANAGEMENT OF HEPATIC FIBROLAMELLAR CARCINOMA
}

\author{
Marlus Moreira $^{1}$; João Eduardo Leal Nicoluzzi ${ }^{2}$ : Pedro Ernesto Caron, TCBC-PR ${ }^{3}$
}

\section{INTRODUÇÃO}

O carcinoma hepatocelular $(\mathrm{CH})$ é um tumor de células parenquimatosas hepáticas, caracterizado por baixa taxa de ressecabilidade, resposta pobre ao tratamento não cirúrgico e menor sobrevida a longo prazo. Contrastando com estas características, pacientes com a variante fibrolamelar do carcinoma hepatocelular apresentam taxas de ressecabilidade mais elevadas e sobretudo longa sobrevida.

As características dos pacientes do grupo fibrolamelar são notavelmente diferentes, com nítida prevalência de jovens, discreto predomínio do sexo feminino e ausência de associação à cirrose ou outras hepatopatias ${ }^{1,2}$. Este tipo de tumor foi descrito pela primeira vez por Edmondson em 1956 ao relatar sobrevida prolongada em paciente de 14 anos após ressecção de tumor hepático primário $^{1,3}$.

Contudo, os estudos publicados em 1980 difundiram as características deste tumor: células eosinofílicas poligonais e trabeculadas separadas por lamelas paralelas de colágeno hialino que cursam com clínica distinta da convencional, com melhor prognóstico, ressecabilidade e crescimento indolente, ocorrendo em jovens não cirróticos, sem associação com o vírus B da hepatite ou elevação da alfa-fetoproteína ${ }^{2,3}$.

Neste artigo descreve-se típico caso de hepatocarcinoma fibrolamelar (HF) com o intuito de apresentar o seu manejo terapêutico o qual difere do que é preconizado para o $\mathrm{CH}$.

\section{RELATO DO CASO}

Paciente branca, sexo feminino, 26 anos, com queixas de massa abdominal e dispepsia. Durante investigação foram realizados testes laboratoriais incluindo provas de função hepática, alfa-fetoproteína, CA 19-9 e antígenocarcinoembrionário os quais demonstraram valores normais. A tomografia de abdome revelou volumosa massa ocupando todo fígado direito, bem delimitado, com veia supra-hepática média deslocada contralateralmente, ausência de linfonodomegalia e fígado esquerdo hipertrofiado (Figura 1).

O tratamento realizado foi hepatectomia direita, conjuntamente com ressecção de parte do diafragma, o qual encontrava-se aderido ao tumor, com 40 minutos de exclusão vascular hepática. A ressecção hepática foi realizada com auxílio de bisturi ultra-sônico, com perda sangüínea mínima, sem necessidade de reposição. No pós-operatório a paciente foi mantida por três dias em UTI com alta hospitalar no $5^{\circ}$ dia após procedimento. A histologia mostrou tecido hepático tumoral compatível com HF (Figura 2). Em seguimento ambulatorial a paciente encontra-se em quimioterapia

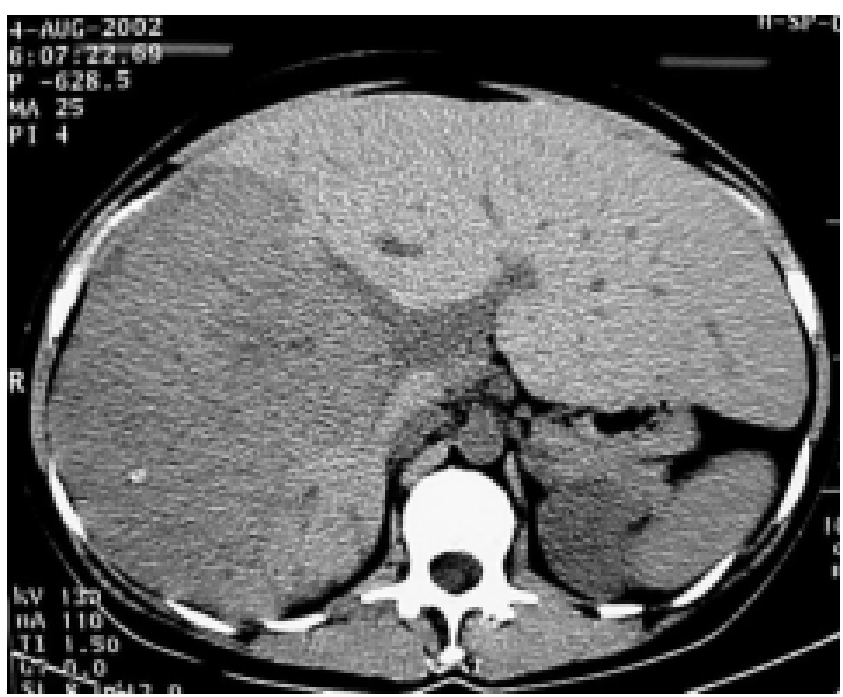

Figura 1 - TC: volumoso tumor ocupando o fígado direito.

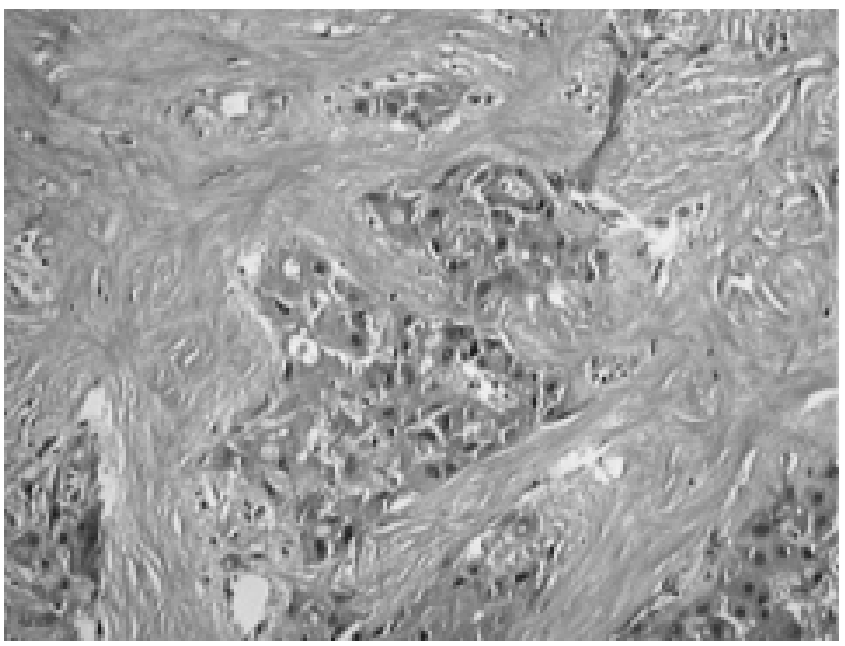

Figura 2 - Carcinoma fibrolamelar: aspecto histológico.

1. Residente $2^{\circ}$ ano Cirurgia-Geral do Hospital Angelina Caron.

2. Cirurgião do Serviço, Especialista em Cirurgia Hepato-Biliar, Hôpital Paul Brousse, Paris; Mestre em Transplantes, Universidade Paris, XI; Doutor em Cirurgia - UFPR.

3. Chefe do Serviço de Cirurgia-Geral do Hospital Angelina Caron; Mestre em Cirurgia pela PUC-PR.

Recebido em 22/09/2003

Aceito para publicação em 05/01/2004

Trabalho realizado no Serviço de Cirurgia-Geral do Hospital Angelina Caron, Campina Grande do Sul, Paraná. 
adjuvante com seguimento de nove meses apresentando exames de controle sem indícios de recidiva ou metástases.

\section{DISCUSSÃo}

$\mathrm{O} \mathrm{HF}$ aparece como uma forma distinta dos tumores de fígado convencionais, acometendo jovens, mais comuns em mulheres e em fígados não-cirróticos ${ }^{1}$. Comparando com o $\mathrm{CH}$, que é a forma mais prevalente dos tumores primários de fígado $^{4,5}$, apenas $20 \%$ tem histologia não-cirrótica ${ }^{4}$, acomete indivíduos mais idosos e a relação homem/mulher é de $6: 1^{1}$. O HF cursa com níveis séricos de alfa-fetoproteína normais, é solitário em $64 \%$ das vezes, multifocal em $36 \%$ e envolve ambos os lobos em 54\%, com taxa de ressecabilidade curativa de $48 \%$ contra apenas $10 \%$ do $\mathrm{CH}$. O último é multifocal em $51 \%$ dos casos e envolve ambos os lobos em $67 \%$ das vezes ${ }^{1}$.

Até 1979 a existência e o significado clínico do diagnóstico de HF não era difundido entre cirurgiões dos EUA, mesmo com a sobrevida destes pacientes excedendo em muito as expectativas ${ }^{3}$. A sobrevida alcançada em cinco anos por pacientes com ressecção completa do tumor fibrolamelar foi de $45 \%$, com média de 50 meses e quando analisada a do $\mathrm{CH}$ foi de $0 \%$ em cinco anos, com média de 22 meses $^{1}$. Nos casos irressecáveis a sobrevida foi de quatro meses e obteve-se oito meses nos que foram tratados com quimioterapia. A diferença não foi significativa quando manejados com radioterapia nos casos de ressecções incompletas ${ }^{1}$.

A hepatectomia sub-total é o tratamento de escolha ${ }^{1,5}$. Contudo, o transplante hepático também é opção acei- tável com sobrevida melhor quando comparada aos manejados com terapias adjuvantes nos casos irressecáveis ou com lesão residual ${ }^{3}$. Starzl et $a l^{3}$ defendem a hepatectomia subtotal mesmo em lesões volumosas compressivas e aderenciais, obtendo benefícios com ressecções em bloco envolvendo estruturas anexas. Até mesmo reoperações com ressecções de metástases linfonodais de tórax, abdome, diafragmáticos e de mediastino médio com acesso combinado abdôminotorácico são de benefício ao paciente, especialmente quando se associa quimioterapia ${ }^{3}$. Em casos selecionados com comprometimento de veias supra -hepáticas, veia cava inferior, tríade portal, recidiva no lobo hepático remanescente e trombos tumorais em grandes vasos está indicada a hepatectomia total com transplante hepático ortotópico ${ }^{3}$. Índices de sobrevida de até 40 meses após transplante foram publicados por estes autores, o que supera em muito os oito meses obtidos quando a lesão não é ressecada, ou ocorre remanescência tumoral, sendo tratados com quimioterapia. Mesmo com risco elevado de recidiva associado à imunossupressão defende-se o transplante para HF baseado no fato de prolongar-se significativamente a sobrevida e de que $50 \%$ destes receptores podem alcançar a cura ${ }^{3}$. Por outro lado nos casos de metástases já instaladas o transplante não é alternativa segura ${ }^{3}$.

Assim é consenso que a variante fibrolamelar quando comparada ao tipo mais comum, que é o $\mathrm{CH}$, representa uma entidade clínico-patológica totalmente distinta. $\mathrm{O}$ tratamento de escolha é a hepatectomia sub-total seguida de quimioterapia adjuvante, sendo o transplante, alternativa real para tratamento em casos selecionados.

\begin{abstract}
Fibrolamellar carcinoma of the liver is a distinct variant of hepatocellular carcinoma characterized by the lack of association with cirrhosis or other underlying liver diseases, as hepatitis B virus. The serum alpha-fetoprotein level is often not elevated, occuring typically in young patients. Distinction from conventional hepatocellular carcinoma is of clinical significance, because prognosis is far better due to higher ressecability and more indolent growth. We describe a case of a 26-year-old woman free of other liver diseases presenting with a large abdominal palpable mass. After ressection by vascular exclusion technique, the pathologic examination revealed fibrolamellar carcinoma. The former should not be confused with the hepatocellular carcinoma, since it is related with a more favorable prognosis (Rev. Col. Bras. Cir. 2005; 32(2): 104-105).
\end{abstract}

Key-words: Liver diseases; Carcinoma, hepatocellular; Liver Neoplasms; Carcinoma.

\section{REFERÊNCIAS}

1. Wood WJ, Rawlings M, Evans H, et al. - Hepatocellular carcinoma: importance of histologic classification as a prognostic factor. Am J Surg. 1988,155(5):663-666.

2. Cheuk W, Chan JK - Clear cell variant of fibrolamellar carcinoma of the liver. Arch Pathol Lab Med. 2001, 125(9):1235-1238

3. Starzl TE, Iwatsuki S, Shaw BW, et al. -Treatment of fibrolamellar hepatoma with partial or total hepatectomy and transplantation of the liver. Surg Gynecol Obstet. 1986,162(2):145-148.

4. Bralet MP, Régimbeau JM, Pineau P, et al. - Hepatocellular carcinoma occurring in nonfibrotic liver: epidemiologic and histopathologic analysis of 80 French cases. Hepatology. 2000, 32(2):200-204
5. Di Bisceglie AM, Carithers RL, Gores GJ - Hepatocellular carcinoma. Hepatology. 1998, 28(4):1161-1165.

Endereço do autor:

Dr. João Eduardo L. Nicoluzzi

Rua: Santo Amaro, 118 Água Verde

80.620-330 - Curitiba - PR

Fone: 41-264-6719

E-mail: jenicoluzz@yahoo.com.br 